\title{
Leucemia em adultos e proximidade de residências das linhas de alta tensão em Uberlândia: Estudo do tipo caso-controle
}

\author{
Maria Clara Nunes de Matos, Alesca Prado de Oliveira, Antônio Marcos Machado de Oliveira, \\ Boscolli Barbosa Pereira
}

\begin{abstract}
Resumo
A definição de saúde defendida pela Organização Mundial da Saúde evidencia a importância do ambiente como determinante da saúde e, dessa forma, considera que o território em que se vive desempenha papel fundamental no entendimento do atual conceito. É nesse sentido que entendemos que a revolução industrial, atrelada ao crescimento econômico e social da sociedade, trouxe como consequência diferentes tipos e fontes poluidoras, das quais destacamos a poluição magnética. A relação entre doenças crônicas e poluição gerada por campos eletromagnéticos tem sido alvo de estudos nos últimos 30 anos e tem demonstrado a importância do ambiente como fator condicionante da saúde. A principal fonte de exposição de humanos a campos magnéticos de extremamente baixa frequência está relacionada à geração, transmissão e uso de energia elétrica e dependem de fatores como distância das linhas de transmissões à residência. O objetivo dessa investigação é avaliar a associação entre casos de leucemias e proximidade das residências em relação às linhas de alta tensão. Trata-se de estudo do tipo caso-controle de base populacional no município de Uberlândia, utilizando dados do Sistema de Informações Hospitalares do SUS (SIH/SUS) e do Setor de Estatísticas e Informações Hospitalares do Hospital de Clínicas de Uberlândia (HCU-UFU) com 1439 pacientes com leucemias (CID 10, C91-95), maiores de 18 anos, diagnosticados em Uberlândia entre 1999-2015. Controles foram pareados segundo proximidade das residências em relação às linhas de alta tensão, idade e sexo. Para avaliar a chance (Odds ratio) de ocorrência de leucemias em relação à distância entre as linhas e as residências, foi realizado teste de regressão logística múltipla e calculados os intervalos de $95 \%$ de confiança. Para o cálculo dos coeficientes de incidência de leucemias, registradas no DATASUS nos anos de 1999-2015, distribuídos por faixa etária e sexo, ajustados para o período avaliado, consideramos o somatório da população do município, segundo dados do recenseamento nos anos 2000 e 2010 multiplicada por 17. Os casos de leucemias foram espacializados na área urbana de Uberlândia, usando a base cartográfica com delimitação dos bairros e seus respectivos setores. Foram feitas extrações das distâncias em relação às redes de alta tensão, agrupadas em: até 100m, >100-300m e >300m. Foram identificados e geocodificados 2992 casos e controles. Foi identificado risco aumentado de leucemia entre adultos que moram mais próximos às linhas de alta tensão, comparados àqueles que moram a mais de $200 \mathrm{~m}$. O maior risco foi encontrado para os que vivem até $50 \mathrm{~m}$ da linha $(\mathrm{OR}=1,68 ; 95 \% \mathrm{IC}=1,41-2,53)$. Foi observado a probabilidade de ocorrência de leucemias levando em consideração fatores de confundimento (sexo e idade), destacando-se maior chance entre indivíduos do sexo masculino, com mais de 60 anos e que residem até $50 \mathrm{~m}$ da linha de transmissão $(54,96 \%)$. Os resultados encontrados sugerem de forma consistente um efeito dose-resposta, evidenciando a possibilidade de aumento de risco de leucemias para indivíduos que residem mais próximos às redes de alta tensão.
\end{abstract}

Descritores: Campos Eletromagnéticos; Leucemia; Epidemiologia. 